\title{
UPPER ATMOSPHERE OF JUPITER-A POST VOYAGER PERSPECTIVE
}

\author{
S. K. Atreya \\ Department of Atmospheric and Ocean Science, \\ Space Physics Research Laboratory, The University of \\ Michigan, Ann Arbor, Michigan 48109, USA
}

From the time of Pioneer observations in 1973-74 to the Voyager encounters in 1979, the Jovian upper atmospheric temperature has increased by about $30 \%$ to a value of $1100 \pm 200 \mathrm{~K}$, the eddy diffusion coeffictent at the homopause decreased by a factor of about $10^{2}$ to a value of $\sim 10^{6} \mathrm{~cm}^{2} \mathrm{~s}^{-1}$, the equatorial disc Lyman alpha intensity increased by a factor of 30 , to $14 \mathrm{kR}$, and the equatorial ionosphere became more extensive and showed diurnal variation. Many of these changes are believed to have resulted from a change in solar activity and the mechanisms responsible for upper atmospheric heating. The upward propagating inertia gravity waves are expected to supply a constant source of heat, not varying with the solar activity. The penetration of the magnetospheric soft electrons, Joule heating mechanism, and auroral electrons comprise important potential candidates for upper atmospheric energetics.

Prior to the Voyager encounters in 1979, most of the information about the composition and structure of the Jovian upper atmosphere was derived from the ground based, rocket, earth orbiting satellite and Pioneer observations. The Voyager ultraviolet spectrometer (UVS) provided the first comprehensive data pertaining to the Jovian atmosphere in the $P \leqslant 10 \mu \mathrm{b}$ region. These data have been supplemented by other Voyager instruments, in particular radioscience (RSS), imaging science (ISS), and the infra-red (IRIS) devices. Figure 1 presents the current status of the Jovian temperature profile. The ground based and Pioneer observations had already revealed that Jupiter radiates nearly two and half times as much energy as it receives from the Sun, and that the upper stratospheric temperature is on the order of $170 \mathrm{~K}$ (see review by Hunten [1]). The Voyager IRIS and RSS data confirmed this result. The Pioneer RSS data of Fjeldbo et al [2] on the ionospheric profiles were the first to suggest a high topside plasma temperature on the order of $850 \mathrm{~K}$, and this led Atreya and Donahue [3] to propose that Jupiter may indeed sustain a corona. The Voyager RSS equatorial data also revealed a high topside plasma temperature as indicated by Eshleman et al [4]. The Voyager 1 UVS data on solar occultation gave the first measurement of 'neutral' temperature in the upper atmosphere. Monitoring of continuum absorption in the 600-730\& range provided the $\mathrm{H}_{2}$ scale height, and the analysis by Atreya et al [5] yielded a neutral temperature of $1450 \pm 250 \mathrm{~K}$ nearly $1500 \mathrm{~km}$ above the ammonla cloud tops. Further analysis of the solar occultation data including the short wavelength internal scattering effects yield the exospheric temperature to be $1100 \pm 200 \mathrm{~K}$. The neutral temperature Is in essential agreement with the plasma temperature, confirming the existence of equilibrium between plasma and neutral temperatures in the topside ionosphere 
proposed by Henry and Mc Elroy [6] for cold exosphere and Nagy et a1 [7] for hot exosphere. The measurement of the neutral temperature between $350 \mathrm{~km}$ and $800 \mathrm{~km}$ is the result of monitoring absorption by $\mathrm{H}_{2}$ and hydrocarbons in the Voyager 2 experiment of the ultraviolet occultation of $\alpha$ Leo. The data on absorption by $\mathrm{H}_{2}$ in the Lyman band system resulted in the scale height, hence the temperature information in the $350-800 \mathrm{~km}$ range; combining these data with the solar occultation data yielded the temperature above $800 \mathrm{~km}$. The stellar occultation data and their analysis are presented in the papers by Atreya et al [22] and Festou et al [8].

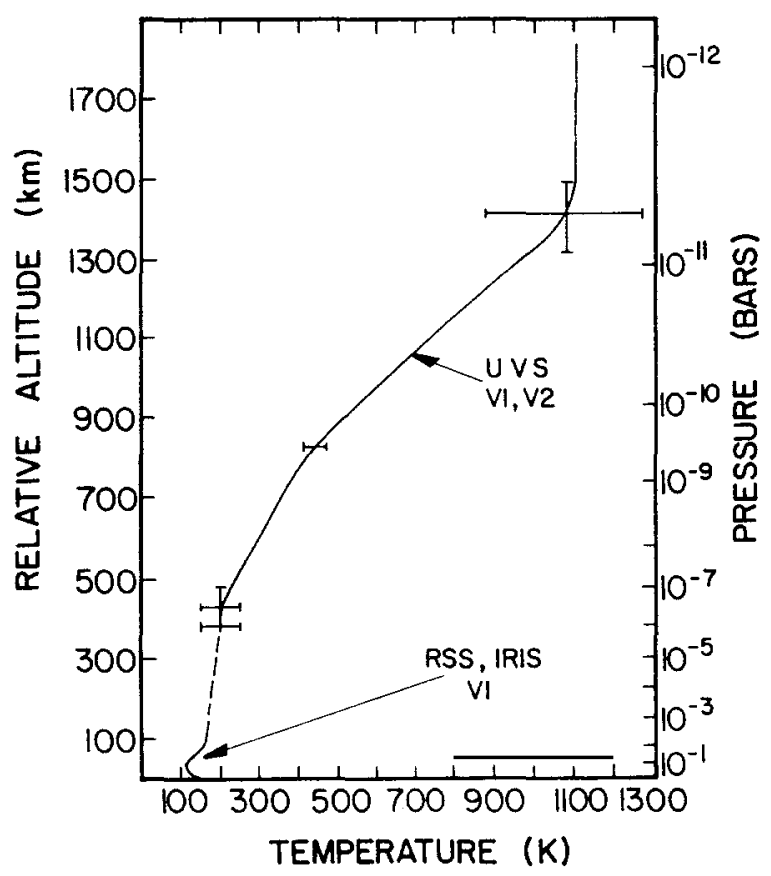

Fig. 1 Temperature vs. altitude above the ammonia cloud tops located at $\sim 600 \mathrm{mb}$, $T=150 \mathrm{k}$. The broken line between $150 \mathrm{~km}$ and $350 \mathrm{~km}$ is an interpolation since no firm data exist in this range. Thermal profile above $800 \mathrm{~km}$ is the one required to reproduce the Voyager 1 UVS solar occultation measurement of the exospheric temperature and the Voyager 2 UVS stellar occultation transmission data below $800 \mathrm{~km}$. Festou et al [8]; Atreya at a1 [22].

Tra high thermospheric temperature and its increase from the solar minimum (Pioneer epoch) to the solar maximum (Voyager encounters) can be accounted for by the mechanisms responsible for upper atmospheric energy deposition. Prior to the Voyager 2 stellar occultation, it appeared from the calculations of Atreya and Donahue [3], and Atreya et al [5] that the upper atmospheric heating may be caused primarily by upward propagating inertia gravity waves, superimposed on which would be a time varying component due to magnetospheric soft electrons proposed by Hunten and Dessler [9], or auroral electrons, an indication of which appears in Broadfoot et al [10], and Sandel et al [11]. The magnetospheric processes are still operative, although their contribution is perhaps important to a lesser 
degree. Additionally, Joule heating mechanism is expected to be significant also. In order for the Joule heating mechanism to work in the Jovian atmosphere, one requires a differential wind of $100-200 \mathrm{~m} \mathrm{~s}^{-1}$ between ions and neutral. Preferably, the mechanism should be operative in the deep atmosphere, at about $10^{12}-10^{14}$ $\mathrm{cm}^{-3}$ leve1, in order to account for the high exospheric temperature. There are no measurements of neutral winds in this region of the Jovian atmosphere.

The next important question about the aeronomy of upper atmosphere concerns the eddy transport coefficient, $K_{h}$, at the homopause. According to Hunten [12] and Wallace and Hunten [13], the intensity of non-auroral Ly afrom the Jovian disc is a measure of the eddy mixing term. From the Jovian Ly $\alpha$ intensity, one can calculate the column abundance of the atomic hydrogen above the level where methane begins to absorb Ly $a$. This level will correspond to the homopause, since densities of methane and other hydrocarbons will drop above this altitude. The eddy diffusion coefficient at the homopause is then related to the atomic hydrogen column abundance by an inverse functional relationship.

The Jovian Ly $a$ intensity has varied from $0.4 \mathrm{kR}$ at the time of solar minimum (Carlson and Judge [14]) to a high of $14 \mathrm{kR}$ at the time of solar maximum (Broadfoot et al [10]). The Jovian Ly $\alpha$ intensity in the medium solar activity period was measured to be between 2.5 to $8 \mathrm{kR}$ by Atreya et al [15], Bertaux et a1 [16], Cochran and Barker [17], and Clarke et al [18]. The first three observations were done with the Princeton high resolution spectrometer aboard Copernicus satellite, and the last one on rocket and IUE. The resultant extremes in values of $\mathrm{K}_{\mathrm{h}}$ are $3 \times 10^{8} \mathrm{~cm}^{2} \mathrm{~s}^{-1}$ at the time of solar minimum to $\sim 10^{6} \mathrm{~cm}^{2} \mathrm{~s}^{-1}$ at the time of the voyager encounter.

One can further deduce $K_{h}$ from the interpretation of the measured ionospheric profile. Atreya et al [19] have found that the Voyager 1 equatorial ionospheric structure which is primarily controlled by photoionization can be satisfactoril. explained with a thermospheric temperature of $\sim 1200 \mathrm{~K}$ and $\mathrm{K}_{\mathrm{h}}=1$ to $3 \times 10^{5} \mathrm{~cm}^{2}$ $\mathrm{s}^{-1}$. The direct measure of the homopause level (hence $K_{h}$, since at the homopause $\mathrm{K}_{\mathrm{h}}$ = molecular diffusion coefficient) is the result of monitoring the hydrocarbon density profiles as a function of height, since the hydrocarbons rapidly drop in density above the homopause because of their large mass. The UVS stellar occultation analysis of Atreya et al [22], and Festou et al [8] yields $k_{h}$ on the order of $(0.8$ to 2.2$) \times 10^{6} \mathrm{~cm}^{2} \mathrm{~s}^{-1}$.

Finally, the only information about the height profiles of the gases in the region $\mathrm{p}<1$ mbar is arrived at by analyzing the $\alpha$ Leo stellar occultation data. The results are shown in Figure 2. The dominant photolysis product of $\mathrm{CH}_{4}$ in the upper atmosphere are found to be $\mathrm{C}_{2} \mathrm{H}_{2}$ and $\mathrm{C}_{2} \mathrm{H}_{6} \cdot$ The volume mixing ratios of $\mathrm{C}_{2} \mathrm{H}_{2}$ and $\mathrm{C}_{2} \mathrm{H}_{6}$ are found to be $\leqslant 5 \times 10^{-6}$, and $2.5 \times 10^{-6}$ at altitudes of $300 \mathrm{~km}$ and $325^{2} \mathrm{~km}$ respectively above the ammonia cloud tops. The IRIS measurements give a value of $-3 \times 10^{-8}\left(\mathrm{C}_{2} \mathrm{H}_{2}\right)$ and $\sim 5 \times 10^{-6}\left(\mathrm{C}_{2} \mathrm{H}_{6}\right)$ deeper in the stratosphere. The upper atmospheric results are consistent with $\mathrm{CH}_{4}$ photolysis there.

A few remarks about the variability of the Jovian Ly $\alpha$ are in order as they pertain to the atomic hydrogen distribution. A factor of 30 increase in the Jovian Ly $\alpha$ intensity from 1973 to 1979 cannot be attributed entirely to a two to threefold increase in the solar Ly $\alpha$ flux and a $30 \%$ increase in the exospheric temperature. Neither can it be due to direct excitation of hydrogen by electron impact since the nighttime value of Jovian Ly $\alpha$ is extremely low. Dissociation of $\mathrm{H}_{2}$ by precipitating electrons could provide a sufficiently large source of atomic hydrogen which would then participate in resonance scattering of the solar Ly $\alpha$ photons. Finally, the IRIS observations by Hanel et al [20], yield $\mathrm{He} / \mathrm{H}_{2}=0.10 \pm 0.03$. 


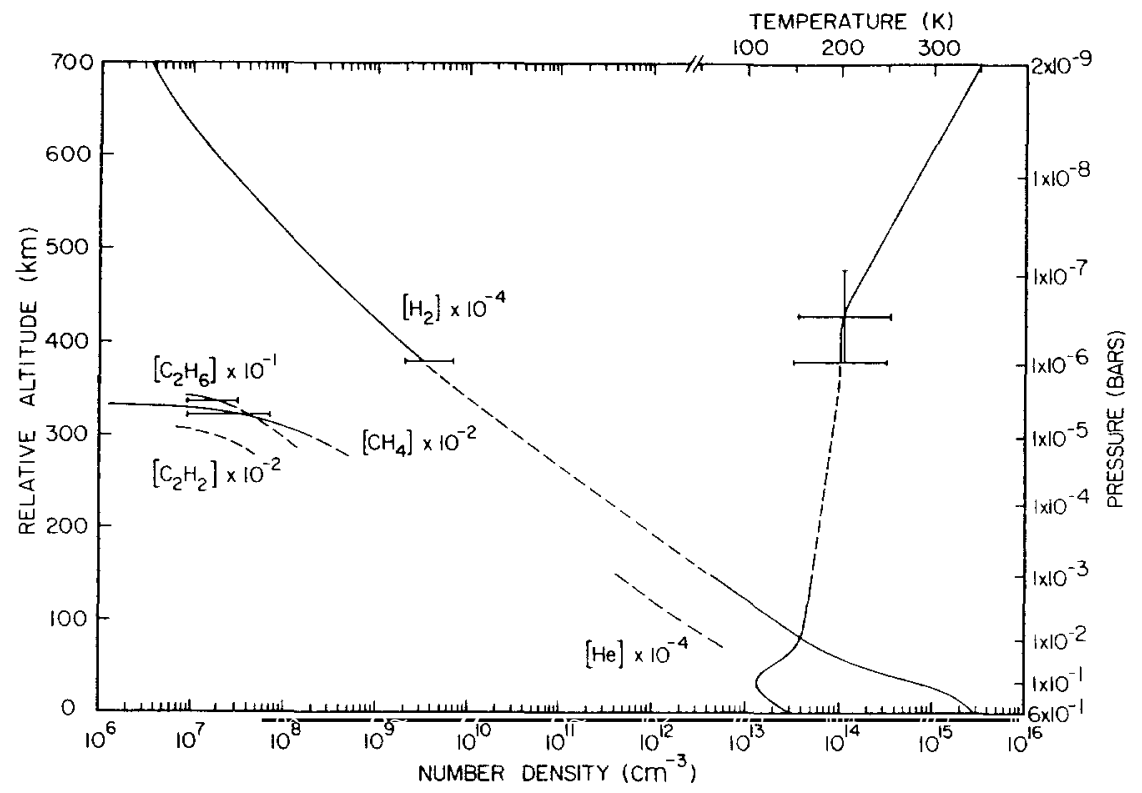

Fir. 2 Number density vs. altitude, and temperature (upper broken abscissa) vs. altitude in the Jovian atmosphere. Pressure corresponding to the altitudes are shown on the right ordinate.

This brief note represents only an extended abstract, and we have discussed only the significant upper atmospheric features as a result of the Voyager observations. A complete account will appear in several papers by Broadfoot et a1 [21]; Festou et al [8]; and Atreya et al [22].

\section{ACKNOWLEDGMENTS}

This research was supported in part by the Planetary Atmospheres Program, of the NASA Solar System Exploration Division, and the NSF Atmospheric Research Section.

\section{REFERENCES}

1. D. M. Hunten, in: Jupiter, University of Arizona Press, 1976, p. 22.

2. G. A. Fjeldbo, A. Kliore, B. Seidel, D. Sweetnam and P. Woiceshyn, in: Jupiter, University of Arizona Press, 1976, p. 238.

3. S. K. Atreya and T. M. Donahue, in: Jupiter, University of Arizona Press, 1976, p. 304 .

4. V. R. Eshleman, G. L. Taylor, G. E. Wood, G. F. Wood, G. F. Lindal, J. D. Anderson, G. S. Levy and T. A. Croft, Science, 204, 976 (1979).

5. S. K. Atreya, T. M. Donahue, B. R. Sande1, A. L. Broadfoot and G. R. Smith, Geophys. Res. Lett., 6, 795 (1979).

6. R. J.W. Henry and M. B. Mc Elroy, J. Atmos. Sci., 26, 913 (1969).

7. A. Nagy, W. Chameides, R. Chen and S. Atreya, JGR, $\overline{81}, 5567$ (1976).

8. M. C. Festou, S. K. Atreya, T. M. Donahue, D. E. Shemansky, B. R. Sandel and A. L. Broadfoot, J. Geophys. Res. (1981), in press.

9. D. M. Hunten and $\bar{A}$. J. Dessler, planet. Space Sci., 25, 817 (1977). 
10. A. L. Broadfoot, M. J. S. Belton, P. Z. Takacs, B. R. Sandel, D. E. Shemans’ay, J. B. Holberz, J. M. Ajello, S. K. Atreya, T. M. Donahue, H. W. Moos, J. L. Bertaux, J. E. Blamont, D. F. Strobel, J. C. Mc Conne1l, A. Dalgarno, R. Goody and M. B. Mc Elroy, Science, 204, 979 (1979).

11. B. R. Sandel, D. E. Shemansky, A. L. Broadfoot, J. L. Bertaux, J. E. Blamont, M. Belton, J. Ajello, J. Holberg, S. Atreya, T. Donahue, H. Moos, D. Strobel, J. Mic Connell, A. Dalgarno, R. Goody, M. Mc Elroy, P. Takacs, Science, 206, 962 (1979).

12. D. M. Hunten, J. Atmos. Sci., 26, 826 (1969).

13. L. Wallace and D. M. Hunten, Astrophys. J., 182, 1013 (1973).

14. R. W. Carlson and D. L. Judge, J. Geophys. Res. 19,3623 (1974).

15. S. K. Atreya, Y. L. Yung, T. M. Donahue and E. S. Barker, Astrophys. J., 218, L83-L87 (1979a).

16. J. L. Bertaux, M. Festou, E. Barker and E. Jenkins. Preprint, Astrophys. J., in press $(1980)$.

17. W. D. Cochran and E. S. Barker. Preprint, Astrophys. J., in press (1980).

18. J. T. Clarke, H. W. Moos, S. K. Atreya and A. L. Lane, Astrophys. J., 241, L179 (1980).

19. S. K. Atreya, T. M. Donahue and J. H. Waite, Jr., Nature, 280, 795 (1979).

20. R. Hanel, B. Conrath, M. Flaser, V. Kunde, P. Lowman, W. Maguire, J. Pearl, J. Pirraglia and R. Samuelson, Science, 204, 972 (1979); Hanel et al. (personal communication, 1981).

21. A. L. Broadfoot, B. R. Sande1, D. E. Shemansky, S. K. Atreya, T. M. Donahue, D. F. Strobel and J. L. Bertaux. Special Voyager J. Geophys. Res. issue (1981), in press.

22. S. K. Atreya, T. M. Donahue and M. C. Festou. Preprint, Astrophys. J. (1981), in press. 